\section{A technical tip in microlipofilling}

\author{
Claudio Bernardi, Paula Giordani Colpo \\ Plastic Surgery Department, Santo Volto \\ Private Hospital, Rome, Italy
}

\begin{abstract}
Lipofilling has become a very important tool in plastic surgery today, since the first experience of autologous fat graft described more than one hundred years ago. Technical developments have led to a more delicate procedure called microlipofilling, in which thin cannulas or needles are used. A frequently discussed technical difficulty is how to inject with a small cannula the fat collected with a larger one. The authors describe their personal maneuver to resolve the above mentioned problem.
\end{abstract}

\section{Introduction}

Since the first experience of autologous fat graft described more than one hundred years ago, ${ }^{1}$ lipofilling has become a commonly used technique in plastic surgery with good to excellent results in relation to low donor-site morbidity, low complication rate, and fast recovery time. It has a wide range of clinical applications, such as facial contouring, breast reconstruction and many other body contouring procedures. $^{2-7}$ There have been a number of attempts to refine or standardize the technique over the years, ${ }^{8-11}$ including the use of small-caliber cannulas particularly useful to treat areas with very thin subcutaneous tissue, resulting in a more delicate procedure called microlipofilling. ${ }^{12-14}$ This term is very appropriate because it defines well the technique, since all maneuvers are gentle and meticulous.

Quite frequently, one of the most discussed technical problem is the difficulty to inject with a thin cannula the fat collected by a larger one: fat aspirated using a cannula with a large diameter section does not pass easily through a smaller one, making the following injections very difficult and hazardous. Often the plunger of the syringe stops because of denser fat or debris and the act of forcing it with heavy pressure of the fingers could lead to accidental injections of the fat in bolus with an imperfect control of the procedure, thus creating deformities. This can be a problem especially when microlipofilling is performed in areas with thin subcutaneous tissue such as in the correction of tear trough, where any irregularity can easily be seen.

\section{Technical note}

We have developed a personal maneuver to resolve the above mentioned problem. We harvested the fat with a $3 \mathrm{~mm}$ cannula and a normal 20 cc syringe since quite often we associate lipofilling with liposuction in trochanteric region or elsewhere. The $3 \mathrm{~mm}$ diameter of the cannula was a good combination with its $20 \mathrm{~cm}$ length to collect a deep yellowish fat with little blood. Should lipofilling be performed alone, a smaller cannula could be used. No specific device was used. During the suction the vacuum was produced and maintained by the palm of the right hand, which blocked the plunger of the syringe. We washed the fat in the syringe by aspirating sterile $0.9 \%$ saline and let it decant for $5 \mathrm{~min}$. If required, the washing procedure can be repeated until the fat is yellow and ready for injection. We transferred it to another syringe by means of the same cannula or needle that we would use for fat injection (Figure 1). Possible stop of the piston could be easily resolved by washing the cannula. A further passage into a 1 cc syringe was done so that at the end of the procedure we had syringes filled up with a very fine fat, ready for injection in the patient. Therefore, microlipofilling was easily performed with no resistance or stop of the piston during the whole procedure using a $0.8 \mathrm{~mm}$ cannula and even using a $21 \mathrm{G}$ needle (Nominal Inner Diameter mm 0.514); Luer-lock syringes were not strictly necessary (Videos 1 and 2). We had
Correspondence: Claudio Bernardi, Plastic Surgery Department, Santo Volto Private Hospital, Piazza del Tempio di Diana 12, 00153 Rome, Italy.

Tel.Fax: +39.06.3213575.

E-mail: claudiobernardi@tiscali.it

Key words: fat graft, lipofilling, microlipofilling.

Conflict of interests: the authors declare no potential conflict of interests.

Received for publication: 27 August 2013.

Revision received: 14 October 2013.

Accepted for publication: 22 October 2013.

This work is licensed under a Creative Commons Attribution NonCommercial 3.0 License (CC BYNC 3.0).

(C) Copyright C. Bernardi and P. Giordani Colpo, 2014 Licensee PAGEPress, Italy

Surgical Techniques Development 2014; 4:5046 doi:10.4081/std.2014.5046

no experience in fat injection with micro-cannulas smaller than $21 \mathrm{G}$.

\section{Conclusions}

In our experience, this procedure has been successfully used in microlipofilling for tear trough (Video 3) or other facial treatments.

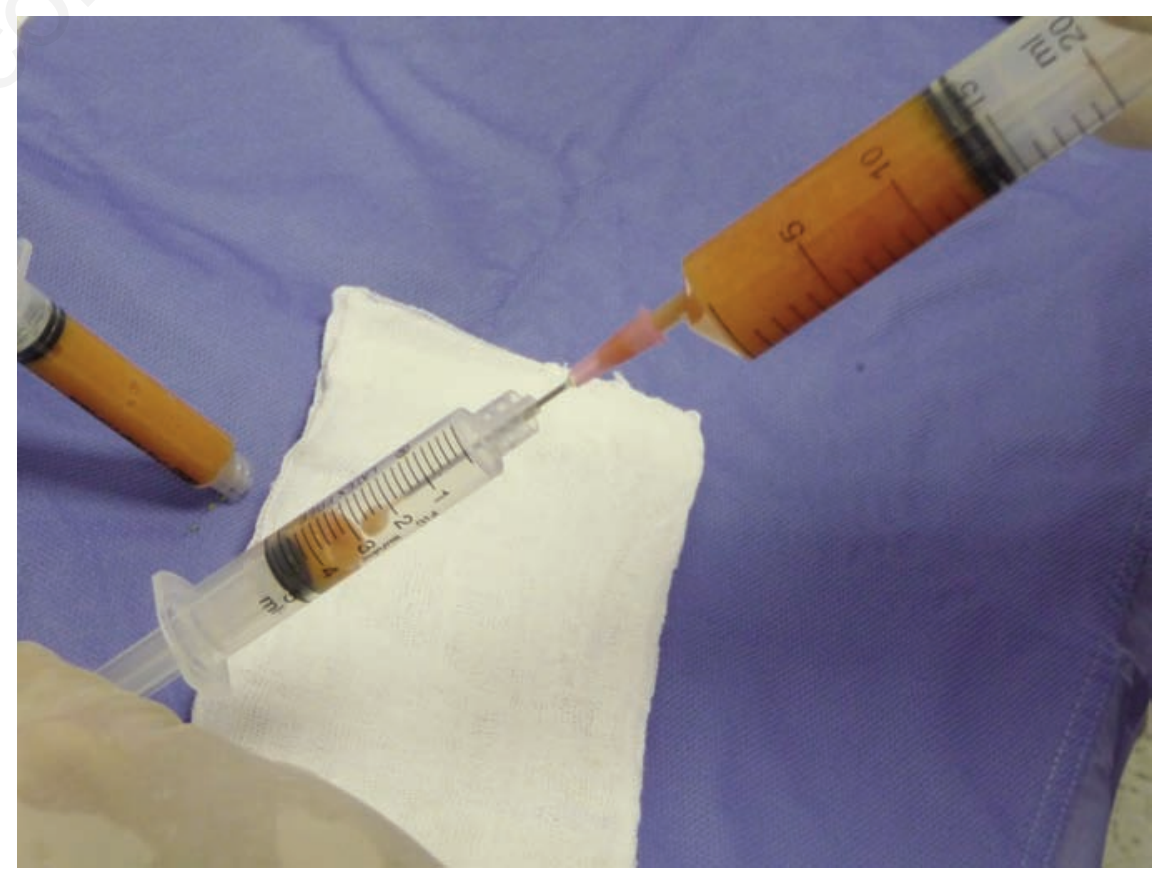

Figure 1. Syringes used in the experiment. 


\section{Supplementary material}

Video 1. Fat transferring from a larger syringe to a smaller one.

Video 2. Fat distribution beside the syringe.

Video 3. Microlipofilling of the tear trough.

\section{References}

1. Neuber F. Fet transplantation. Chir Kongr Verhandl Dtsch Ges Chir 1893;22:66.

2. Illouz YG. The fat cell graft: a new technique to fill depression. Plast Reconstr Surg 1986;78:122.

3. Lambros V. Fat injection for the aging midface. Oper Tech Plast Reconstr Surg 1998;5:129-37.

4. Coleman SR. Hand rejuvenation with structural fat grafting. Plast Reconstr Surg 2002;110:1731-44.

5. Toledo LS, Mauad R. Fat injection: a 20- year revision. Clin Plast Surg 2006;33:4753.

6. Rigotti G, Marchi A, Galiè M, et al. Clinical treatment of radioterapy tissue damage by lipoaspirate transplant: a healing process mediated by adipose-derivated adult stem cells. Plast Reconstr Surg 2007;119:140922.

7. Delay E, Garson S, Tousson G, Sinna R. Fat injection to the breast: technique, results, and indications based on 880 procedures over 10 years. Aesthet Surg J 2009;29:36076.

8. Coleman SR. Long-term survival of fat transplants: controlled demonstrations. Aesthet Plast Surg 1995;19:421-5.

9. Nordstrom REA. "Spaghetti" fat grafting: a new technique. Plast Reconstr Surg 1999;917:1997.

10. Galiè $M$, Pignatti $M$, Scambi $I$, et al. Comparison of different centrifugation protocols for the best yield of adipose-deri- ved stromal cells from lipoaspirates. Plast Reconstr Surg 2008;122:233-4.

11. Condé-Green A, de Amorim NF, Pitanguy I. Influence of decantation, washing and centrifugation on adipocyte and mesenchymal stem cell content of aspirated adipose tissue: A comparative study. J Plast Reconstr Aes 2010;63:1375-81.

12. Guerrerosantos J, Haidar F, Paillet JC. Aesthetic facial contour augmentation with microlipofilling. Aesthet Surg J 2003; 23:239-47.

13. Bernardi C. Microlipofilling in periorbital region. In: Proc. XX Int. Congr. on Aesthetic Plastic Surgery - ISAPS, San Francisco, USA, 14-18 August 2010.

14. Nguyen PS, Desouches C, Gay AM, et al. Development of micro-injection as an innovative autologous fat graft technique: the use of adipose tissue as dermal filler. $\mathrm{J}$ Plast Reconstr Aes 2012;65:1692-9. 